\title{
Intensidade de desfolha e produção de forragem do capim-tanzânia irrigado na primavera e no verão
}

\author{
Geraldo Bueno Martha Júnior(1), Moacyr Corsi( ${ }^{(2)}$, Luis Gustavo Barioni ${ }^{(1)}$ e Lourival Vilela(1)
}

(1)Embrapa Cerrados, BR 020, Km 18, Caixa Postal 08223, CEP 73310-970 Planaltina, DF. E-mail: gbmartha@cpac.embrapa.br, barioni@cpac.embrapa.br, Ivilela@cpac.embrapa.br (2)Universidade de São Paulo, Escola Superior de Agricultura Luiz de Queiroz, Dep. de Zootecnia, Av. Pádua Dias, 11, Caixa Postal 09, CEP 13418-900 Piracicaba, SP. E-mail: moa@esalq.usp.br

Resumo - O objetivo deste trabalho foi determinar o efeito da intensidade de desfolha em Panicum maximum cv. Tanzânia irrigado sobre os componentes da produção forrageira. O delineamento experimental foi em blocos completos casualizados, no esquema de medidas repetidas no tempo, com quatro repetições. Nas parcelas, avaliou-se o efeito do resíduo pós-pastejo $(1.210,3.036$ e $5.471 \mathrm{~kg} / \mathrm{ha}$ de matéria seca do tecido verde da pastagem, folhas e hastes; nas subparcelas, o efeito do período de rebrota $(9,18$ e 27 dias depois da adubação nitrogenada) sobre os componentes da produção de forragem durante a primavera e o verão. A massa de matéria seca total de forragem, a massa da matéria seca de tecido verde de forragem (folhas+hastes) e a massa de matéria seca de folhas aumentaram linearmente $(\mathrm{P}<0,05)$ com os acréscimos na massa de forragem residual e nos dias de rebrota. Nas duas épocas, observou-se interação significativa $(\mathrm{P}<0,05)$ entre o período de rebrota e o resíduo pós-pastejo em relação à massa de matéria seca de hastes. No verão, a relação folha/haste diminuiu com o aumento da massa de forragem residual, mas na primavera houve interação significativa entre o período de rebrota e o resíduo pós-pastejo. A quantidade de material morto aumentou com o período de rebrota. O resíduo pós-pastejo, considerando um ciclo de pastejo de 36 dias, deve ser de 1.650 a $2.700 \mathrm{~kg} / \mathrm{ha}$ de massa de matéria seca de tecido verde de forragem, para assegurar que a produção de folhas e a relação folha/haste se aproximem do máximo.

Termos para a indexação: Panicum maximum, manejo da pastagem, pastagem tropical, resíduo pós-pastejo.

\section{Grazing intensity on herbage production of irrigated tanzania grass pasture during the spring and summer}

Abstract - This experiment aimed to determine the effect of grazing intensity in irrigated Panicum maximum cv. Tanzania on forage production components. A randomized complete block design with four replicates, following a repeated measure arrangement, was used. In the plots, the effect of post-grazing residues $(1,210,3,036$ and $5,471 \mathrm{~kg} / \mathrm{ha}$ of green dry matter - GDM) on forage production components during the spring and summer was tested and, in the subplots, the effect of length of regrowth (9, 18 and 27 days after nitrogen fertilization) was studied. Total herbage dry mass, green herbage dry mass (leaves+stems) and leaf dry mass linearly increased $(\mathrm{P}<0.05)$ with increasing residual stubble mass or days of regrowth. A significant interaction $(\mathrm{P}<0.05)$ between length of regrowth and post-grazing residue was observed for stem dry mass in both seasons. During the summer, the leaf/stem ratio decreased with increasing post-grazing residue, but in the spring, the interaction between regrowth period and post-grazing residue was significant. The quantity of dead material increased with the length of regrowth. The residual stubble mass for irrigated, N-fertilized Tanzania grass pasture, during the spring and summer, considering a 36-day grazing cycle, should be around 1,650 to 2,700 kg/ha of GDM to ensure that leaf production and leaf/stem ratio be close to the maximum.

Index terms: Panicum maximum, grazing management, tropical pasture, post-grazing residues.

\section{Introdução}

Nos últimos anos, o capim-tanzânia (Panicum maximum cv. Tanzânia) tornou-se uma das principais opções forrageiras para sistemas intensivos de produção animal a pasto. Essa forrageira, a exemplo de ou- tras cultivares de $P$. maximum, é exigente em manejo, especialmente em relação à intensidade de desfolha, que condiciona a velocidade de rebrota da planta imediatamente depois do pastejo. Todavia, existem poucas informações sobre qual intensidade de desfolha deve ser imposta ao capim-tanzânia. 
Em estudo realizado no período de setembro/95 a setembro/96, Cecato et al. (2000) verificaram que a altura residual de corte $(20 \mathrm{ou} 40 \mathrm{~cm}$ ) não teve efeito na produção do capim-tanzânia. Os autores concluíram que o capim-tanzânia poderia ser manejado mais baixo, sem prejuízos na produção de forragem. Em trabalho desenvolvido de dezembro a abril, Cecato et al. (2001) verificaram que a utilização do capim-tanzânia, em pastejo com lotação contínua, poderia ser feita nas alturas de 20 a $80 \mathrm{~cm}$, sendo aconselhável evitar intensidades de desfolha próximas a esses limites. Posteriormente, Cecato et al. (2002) concluíram que o manejo do capim-tanzânia, no período de janeiro a abril, deveria situar-se entre 40 a $60 \mathrm{~cm}$ de altura.

Entretanto, as metas de manejo determinadas para o pastejo com lotação contínua não são aplicáveis ao pastejo rotacionado. Ademais, a utilização da altura como índice de manejo deve ser encarada com cautela, uma vez que a estrutura da vegetação de $P$. maximum, para uma dada altura de pastejo, é alterada ao longo dos ciclos de crescimento. No estudo de Quadros et al. (2002), alturas residuais no capim-tanzânia, variando de 32 a $36 \mathrm{~cm}$, corresponderam a resíduos pós-pastejo de 3,0 a 5,6 t/ha de matéria seca de tecido verde (MSV), respectivamente.

Como critério alternativo de manejo, pode-se utilizar a massa de forragem residual. Barbosa et al. (2002) trabalhando com massas de forragem residual de 2,3 e 3,6 t/ha de massa de matéria seca, em capim-tanzânia, no período de 4/11 a 16/12, observaram que em razão de adaptações fisiológicas das plantas, o potencial de produção de forragem não foi alterado pelos resíduos. Em experimento com duração de 14 meses, envolvendo três massas de forragem residuais - 1.266, 2.915 e 4.256 kg/ha de MSV - em capim-tanzânia irrigado, Penat (2002) concluiu que a melhor estratégia para conciliar elevada produtividade de forragem com alta produtividade animal seria a utilização do resíduo intermediário. Esse resultado contrasta com o de Euclides et al. (1993), que constataram não haver benefícios substanciais no incremento do ganho de peso dos animais a partir de $900 \mathrm{~kg} / \mathrm{ha}$ de MSV. Essas diferenças podem ser atribuídas, em grande parte, ao método de pastejo utilizado nos dois estudos, rotacionado no experimento de Penati (2002) e sob lotação contínua no trabalho de Euclides et al. (1993). Entretanto, o máximo resíduo pós-pastejo avaliado no estudo de Euclides et al (1993) foi de $1.100 \mathrm{~kg} / \mathrm{ha}$ de MSV. Em razão desse limite ser muito próximo ao resíduo ótimo preconiza- do pelos autores (900 kg/ha de MSV), pode-se inferir que a falta de contraste satisfatório na amplitude de resíduos pós-pastejo testados não elimina a hipótese de que melhores ganhos de peso poderiam ser obtidos em maiores massas de forragem residuais.

Informações quantitativas dos componentes da produção de forragem (folha, haste e material morto), em uma amplitude de massas de forragem residuais, são imprescindíveis para decidir sobre a intensidade de desfolha a ser praticada no capim-tanzânia. Todavia, informações desta natureza são quase inexistentes nas situações em que essa forrageira é manejada rotacionalmente, com base na massa de matéria seca residual, como ocorreu no trabalho de Barbosa et al. (2002), em que apenas dois resíduos pós-pastejo foram considerados e, no experimento de Penati (2002), em que a análise dos resultados considerou as massas de forragem residuais de modo qualitativo.

O objetivo deste trabalho foi determinar o efeito da intensidade de desfolha em pastagem irrigada de $P$. maximum cv. Tanzânia sobre os componentes da produção forrageira.

\section{Material e Métodos}

Dois experimentos, correspondentes às épocas de primavera ( 24 de outubro a 25 de dezembro de 2000) e de verão ( 29 de novembro de 2000 a 30 de janeiro de 2001), foram realizados em pastagem irrigada de $P$. maximum cv. Tanzânia, em área experimental da Escola Superior de Agricultura Luiz de Queiroz, Universidade de São Paulo, Piracicaba, SP (22041'30" S, $47^{\circ} 38^{\prime} 0^{\prime \prime} \mathrm{W}$, altitude de $580 \mathrm{~m}$ ). A irrigação foi feita por pivô central, de modo a atingir a capacidade de campo quando tensiômetros instalados na profundidade de $20 \mathrm{~cm}$ indicaram potencial de água no solo de -30 a $-40 \mathrm{kPa}$. Algumas características do clima, durante os períodos experimentais, são apresentadas na Figura 1.

O solo da área experimental, classificado como Argissolo Vermelho de textura argilosa, apresentava $33 \%$ de areia, $23 \%$ de silte e $44 \%$ de argila na camada de 0-20 cm de solo. As principais características químicas, nessa camada, foram: matéria orgânica, $25 \mathrm{~g} / \mathrm{kg}$; $\mathrm{pHCaCl}_{2}, 5,1 ; \mathrm{P}$ (resina), $19 \mathrm{mg} / \mathrm{dm}^{3}$; e K, Ca, $\mathrm{Mg}$ e H+Al, 4,$2 ; 40,8 ; 20,9$ e $38,0 \mathrm{mmol}_{\mathrm{c}} / \mathrm{dm}^{3}$, respectivamente. A correção e a adubação do solo foram realizadas de modo a elevar a saturação por bases para $70 \%$ e o teor de $\mathrm{P}\left(\right.$ resina) e a proporção de $\mathrm{K}$ no solo para $20 \mathrm{mg} / \mathrm{dm}^{3} \mathrm{e}$ 4 a $5 \%$ da CTC, respectivamente. Detalhes adicionais 
da área experimental foram apresentados por Penati (2002).

Nos experimentos de primavera e de verão, o delineamento experimental foi em blocos completos casualizados, com quatro repetições, no esquema de medidas repetidas no tempo. Em cada uma dessas épocas, registraram-se três resíduos pós-pastejo nas parcelas e três períodos de rebrota nas subparcelas. $\mathrm{O}$ objetivo inicial foi atingir massas de forragem residuais de $1.000,2.500$ e $4.000 \mathrm{~kg} /$ ha de MSV. Entretanto, os valores médios observados, nas duas épocas, foram de 1.210, 3.036 e $5.471 \mathrm{~kg} / \mathrm{ha}$ de MSV no resíduo pós-pastejo, respectivamente (Penati, 2002). As alturas correspondentes a esses resíduos pós-pastejo foram de 24, 45 e $61 \mathrm{~cm}$, respectivamente (Penati, 2002). O período de rebrota foi representado por avaliações realizadas aos 9,18 e 27 dias depois da adubação nitrogenada $(80 \mathrm{~kg} / \mathrm{ha}$ de $\mathrm{N}$ por ciclo de pastejo), que ocorreu dois dias após a saída dos animais dos piquetes. O ciclo de pastejo, de 36 dias, consistiu de três dias de ocupação e 33 dias de descanso. O pastejo foi feito por machos castrados da raça Nelore de 19 a 24 meses de idade.

Uma unidade amostral de 2x2 m, com uma touceira do capim no seu centro geométrico, foi locada aleatori amente em cada bloco $\left(1.333 \mathrm{~m}^{2}\right)$. O corte de amostragem da forragem, de acordo com os tempos de rebrota indicados anteriormente, foi feito ao nível do solo. A forragem colhida nos $4 \mathrm{~m}^{2}$ da unidade amostral foi pesada antes e depois da secagem em estufa com ventilação forçada de ar $\left(60^{\circ} \mathrm{C}\right.$ por 72 horas). $\mathrm{O}$ valor resultante correspondeu à massa de matéria seca de forragem da pastagem (MFP, kg/ha). Uma subamostra do

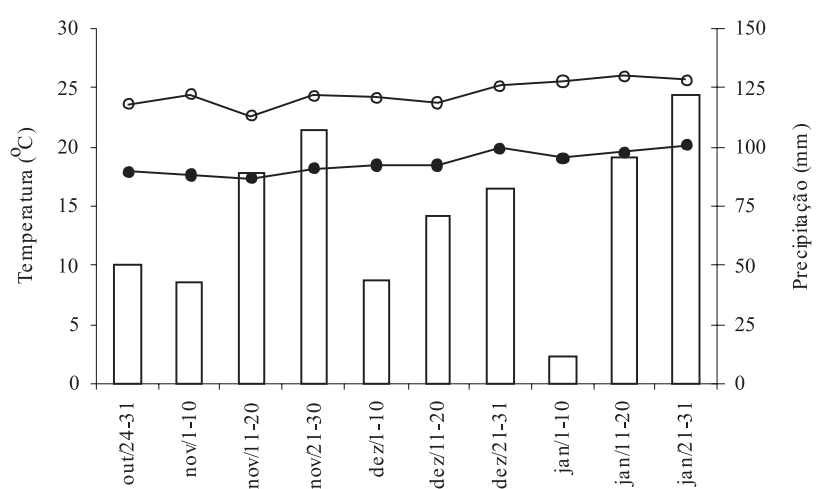

Figura 1. Temperaturas mínimas (•) e médias (o) e precipitação pluvial acumulada ( $\square$ ) em diferentes intervalos de tempo durante os períodos experimentais de primavera e de verão. material proveniente da touceira central de cada unidade amostral foi separada em folhas verdes (lâminas foliares), hastes verdes (caule+bainha) e material morto (folhas e hastes senescidas). O material foi considerado morto quando apresentava mais de $50 \%$ de tecido senescente. A massa de matéria seca desses componentes foi determinada em estufa com ventilação forçada de ar $\left(60^{\circ} \mathrm{C}\right.$ por 72 horas). A resultante proporção de folha, haste e material morto, multiplicada pela MFP, possibilitou calcular a massa de matéria seca de forragem de folhas (MFF), de hastes (MFH) e de material morto (MFM), expressas em kg/ha. A soma de MFF e de MFH representou a massa de matéria seca de forragem verde da pastagem (MFVP). A razão entre os valores de MFF e de MFH correspondeu à relação folha/ haste $(\mathrm{F} / \mathrm{H})$ da pastagem.

A análise dos resultados considerou os resíduos póspastejo observados. Os dados foram testados quanto à homogeneidade de variância e normalidade dos erros e na análise de variância, as equações de regressão e as correlações foram realizadas utilizando-se os recursos do programa estatístico SAS System (SAS Institute, 1989). Em caso de interação significativa $(P<0,05)$ entre a massa de forragem residual e o período de rebrota depois da adubação, os efeitos principais foram desconsiderados, sendo a análise estatística centrada na interação desses fatores. Quando os efeitos do resíduo pós-pastejo e do período de rebrota depois da adubação foram significativos, porém, não se detectou efeito significativo da interação entre esses dois fatores; optouse por análises de regressão múltiplas envolvendo o resíduo e o período, ao invés de análises de regressão simples com apenas um desses fatores. As discussões relativas às equações exponenciais foram feitas com base na derivada primeira das equações.

\section{Resultados e Discussão}

O resíduo pós-pastejo e o período pós-adubação afetaram a MFP. As taxas de acúmulo da MFP, de $243 \mathrm{~kg} /$ ha/dia na primavera e de $252 \mathrm{~kg} / \mathrm{ha}$ /dia no verão, foram superiores aos valores obtidos com capim-tanzânia por Santos et al. (1999), Tosi (1999) e Barbosa et al. (2002) (Figura 2). A utilização de irrigação e de elevados níveis de adubação, principalmente a nitrogenada, justifica essa resposta mais favorável.

O período avaliado, de 11 a 29 dias de rebrota depois da saída dos animais dos piquetes, corresponde à fase linear de incremento na massa de matéria seca de for- 
ragem da pastagem. Quando se considerou todo o período de rebrota, essas taxas de acúmulo diminuíram, refletindo a contabilização da "fase lag" que ocorre nos primeiros dias de rebrota, em que o crescimento da planta forrageira é mais lento (Parsons \& Chapman, 2000).
Tomando como base o resíduo pós-pastejo e considerando a MFP 27 dias após a adubação, calculam-se taxas de acúmulo de $156 \pm 16$ e $170 \pm 22$ kg/ha/dia de matéria seca na primavera e no verão, respectivamente. Esses valores são semelhantes àqueles apontados por San-
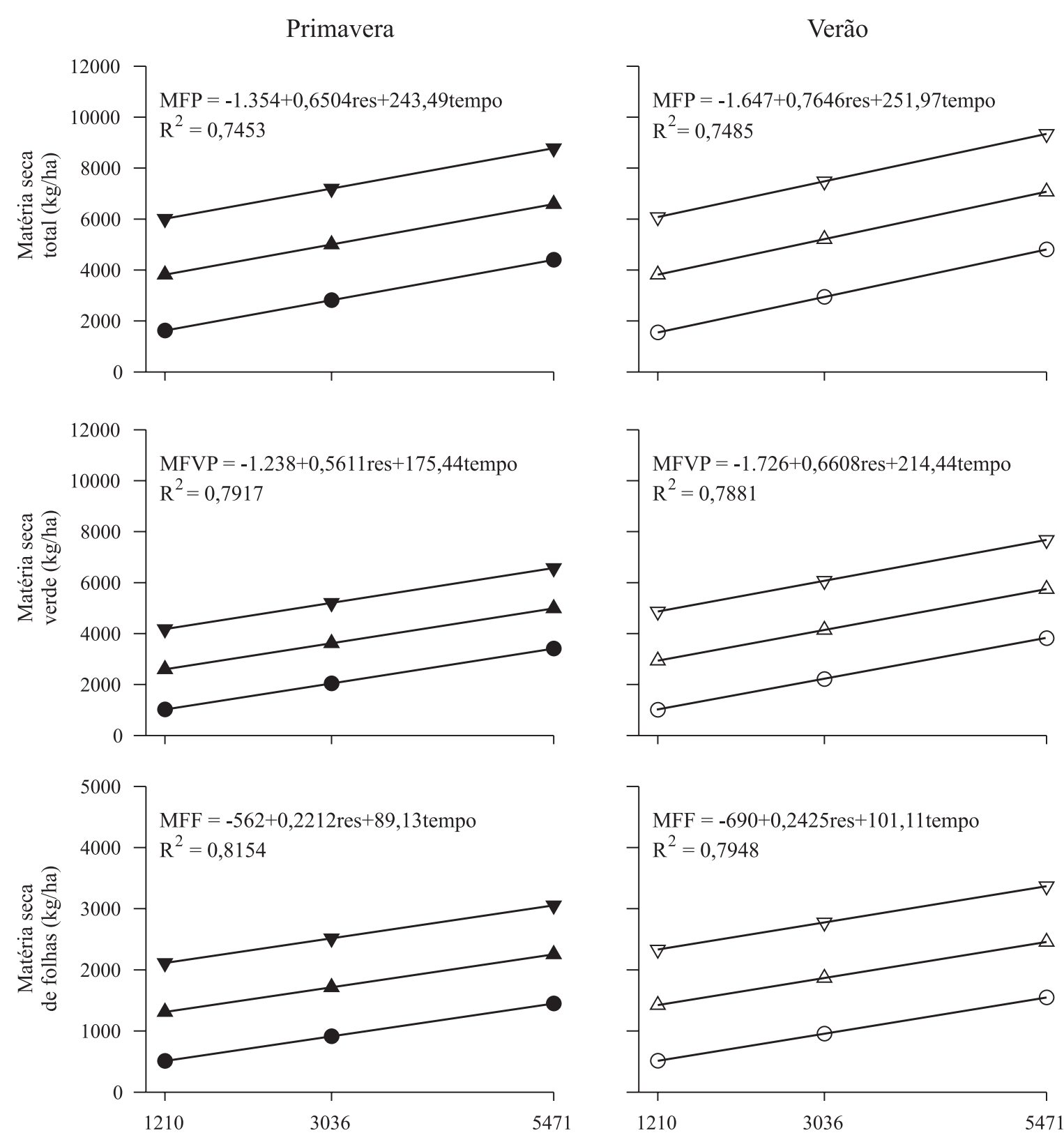

Resíduo pós-pastejo (kg/ha de MSV)

Figura 2. Efeito do resíduo pós-pastejo (res; kg/ha de matéria seca de tecido verde) e do período pós-adubação de $9(\bullet, o), 18(\triangle, \Delta)$ e $27(\nabla, \boldsymbol{\nabla})$ dias, na massa de forragem da pastagem (MFP), massa de forragem verde da pastagem (MFVP) e massa de folhas (MFF), em pastagem de capim-tanzânia na primavera e no verão. As equações apresentadas são significativas $(\mathrm{P}<0,0001)$. 
tos et al. (1999) e Tosi (1999), e superiores aos indicados por Barbosa et al. (2002).

O resíduo pós-pastejo não teve efeito sobre as taxas de acúmulo de forragem quando todo o período de rebrota foi considerado, o que corrobora os resultados de Barbosa et al. (2002). Na primavera, as taxas de acúmulo da MFP foram de $158 \pm 28,152 \pm 27$ e $157 \pm 40$ $\mathrm{kg} / \mathrm{ha} / \mathrm{dia}$ de matéria seca nos resíduos de 1.210, 3.036 e $5.471 \mathrm{~kg} / \mathrm{ha}$ de MSV, respectivamente. Os respectivos valores, no verão, foram 137 $\pm 10,187 \pm 36$ e $195 \pm 69 \mathrm{~kg} / \mathrm{ha} / \mathrm{dia}$

O efeito do resíduo pós-pastejo sobre a MFP foi menor do que o efeito do período de rebrota (Figura 2). O incremento de $1 \mathrm{~kg} / \mathrm{ha}$ de MSV no resíduo pós-pastejo determinou acréscimos de 0,65 e $0,76 \mathrm{~kg} / \mathrm{ha}$ na MFP durante a primavera e o verão, respectivamente. Calcula-se que aumentos de 375 e $332 \mathrm{~kg} / \mathrm{ha}$ de MSV no resíduo pós-pastejo, na primavera e no verão, respectivamente, teriam impacto semelhante a um dia de rebrota na MFP.

A taxa média de aumento na MFM correspondeu a $14 \%$ da MFP na primavera e no verão, uma vez que o aumento de uma unidade no resíduo pós-pastejo determinou incrementos de $0,56 \mathrm{~kg} / \mathrm{ha}$ na MFVP na primavera e de $0,66 \mathrm{~kg} / \mathrm{h}$ a na MFVP no verão (Figura 2). Quando o período pós-adubação foi considerado, a taxa de acréscimo na MFM representou $28 \%$ da MFP na primavera e $14 \%$ da MFP no verão, posto que a MFVP, nessas épocas, aumentou em 175 e $214 \mathrm{~kg} / \mathrm{ha} / \mathrm{dia}$, respectivamente (Figura 2). Não se observou efeito do resíduo pós-pastejo sobre a variável MFM. Esse comportamento contrasta com o observado por Cecato et al. (2001), que encontraram efeito significativo da altura de manejo do capim-tanzânia sob lotação contínua sobre a massa de matéria seca de material morto. Contudo, Zimmer (1999) e Penati (2002) observaram efeitos inconsis tentes do resíduo pós-pastejo sobre a quantidade de material morto em diferentes épocas de avaliação no ano.

O período depois da adubação influenciou a MFM havendo, no entanto, pequenas diferenças nos valores da quantidade de material morto nas avaliações realizadas durante a primavera (MFM $=312,85+50,95$ tempo; $\left.\mathrm{R}^{2}=0,9767 ; \mathrm{P}<0,0001\right)$ e o verão $(\mathrm{MFM}=151,86+59,50$ tempo; $\left.\mathrm{R}^{2}=0,9974 ; \mathrm{P}<0,0001\right)$. Os acréscimos na MFM/tecido senescente na pastagem, com o aumento do intervalo de rebrota, provavelmente refletiram condições menos favoráveis de quantidade e qualidade de luz no interior da cobertura vegetal com o avançar da rebrota da pastagem, que favoreceram o processo de senescência (Parsons \& Chapman, 2000).

O incremento de $1 \mathrm{~kg} / \mathrm{ha}$ de MSV no resíduo póspastejo determinou acréscimos médios de $0,22 \mathrm{~kg} / \mathrm{ha}$ na MFF na primavera e de $0,24 \mathrm{~kg} / \mathrm{ha}$ na MFF no verão (Figura 2). Em relação ao efeito do período pós-adubação, verificaram-se aumentos médios na massa de matéria seca de folhas de $89 \mathrm{~kg} / \mathrm{ha} /$ dia na primavera e de $101 \mathrm{~kg} / \mathrm{ha} /$ dia no verão, para o incremento de um dia no período de rebrota (Figura 2). Quanto à MFH, constatou-se efeito da interação entre o período pós-adubação e o resíduo pós-pastejo. Considerando o período de rebrota na primavera e no verão, verificou-se que a MFH apresentou valores semelhantes nos resíduos intermediário e leniente, particularmente depois de 18 dias da adubação nitrogenada (Figura 3). A MFH mostrou padrão semelhante de resposta em face do aumento no resíduo pós-pastejo nas avaliações efetuadas aos 18 e 27 dias depois da adubação (Figura 3).

O efeito positivo do aumento no resíduo pós-pastejo sobre a MFF e a MFH pode ser atribuído à manutenção de condições mais favoráveis de índice de área foliar residual, que permite maior interceptação de luz e, conseqüentemente, maiores taxas de fotossíntese logo depois do pastejo; reservas fisiológicas na planta, com efeito favorável sobre o crescimento da forrageira no início do período de rebrota, quando se verifica baixo índice de área foliar residual e atividade fotossintética reduzida; e crescimento de raízes, que favorece a aquisição de água e de nutrientes para sustentar o crescimento da planta imediatamente depois da desfolha (Gomide et al., 1979; Thornton \& Millard, 1996; Pagotto, 2001; Mello, 2002). A desfolha leniente pode ainda ter contribuído para a menor eliminação de meristemas apicais, favorecendo a velocidade e o vigor de rebrota (Gomide et al., 1979). A ação conjunta de IAF residual mais elevado, status mais favorável de reservas fisiológicas na planta, maior crescimento de raízes e menor eliminação de pontos de crescimento provavelmente contribuiram para o restabelecimento de condições fisiológicas favoráveis à rápida recuperação da planta forrageira logo depois do pastejo.

O aumento no tempo de rebrota potencializou a ação favorável do maior resíduo pós-pastejo na produção da pastagem (Figuras 2 e 3), possivelmente, em razão de acréscimos no IAF (Mello, 2002) e no crescimento de raízes (Pagotto, 2001), que possibilitam o rápido restabelecimento de balanço positivo de carbono na 
planta subseqüentemente ao pastejo (Thornton \& Millard, 1996; Corsi et al., 2001). De fato, incrementos na massa de forragem residual de 318 e de $413 \mathrm{~kg} / \mathrm{ha}$ de MSV, na média de primavera e de verão, tiveram efeito similar ao obtido com apenas um dia de rebrota sobre MFVP e a MFF, respectivamente (Figura 2). Entretanto, nem sempre se observa efeito positivo da menor intensidade de pastejo sobre a produção de forragem. Cecato et al. (2000) observaram relação inversa entre a altura residual de desfolha e a massa de matéria seca de folhas. Nos cortes de 20 e $40 \mathrm{~cm}$ de altura, a quanti- dade de folhas acumuladas em quatro ciclos de crescimento de verão foi de 13,6 e 11,0 t/ha, respectivamente. Nesse período, a MFVP foi de 16,6 t/ha na altura residual de $20 \mathrm{~cm}$ e de $12,3 \mathrm{t} /$ ha nos cortes feitos a $40 \mathrm{~cm}$. $\mathrm{O}$ acréscimo na MFF, em resposta ao aumento do resíduo pós-pastejo, representou, na média das duas épocas, $38 \%$ do incremento observado na MFVP (Figura 2). Quando o tempo de rebrota foi considerado, a MFF correspondeu, na média de primavera e de verão, a 49\% do aumento na MFVP (Figuras 2), ou seja, aumentos no resíduo pós-pastejo possibilitaram maior

\section{Primavera}
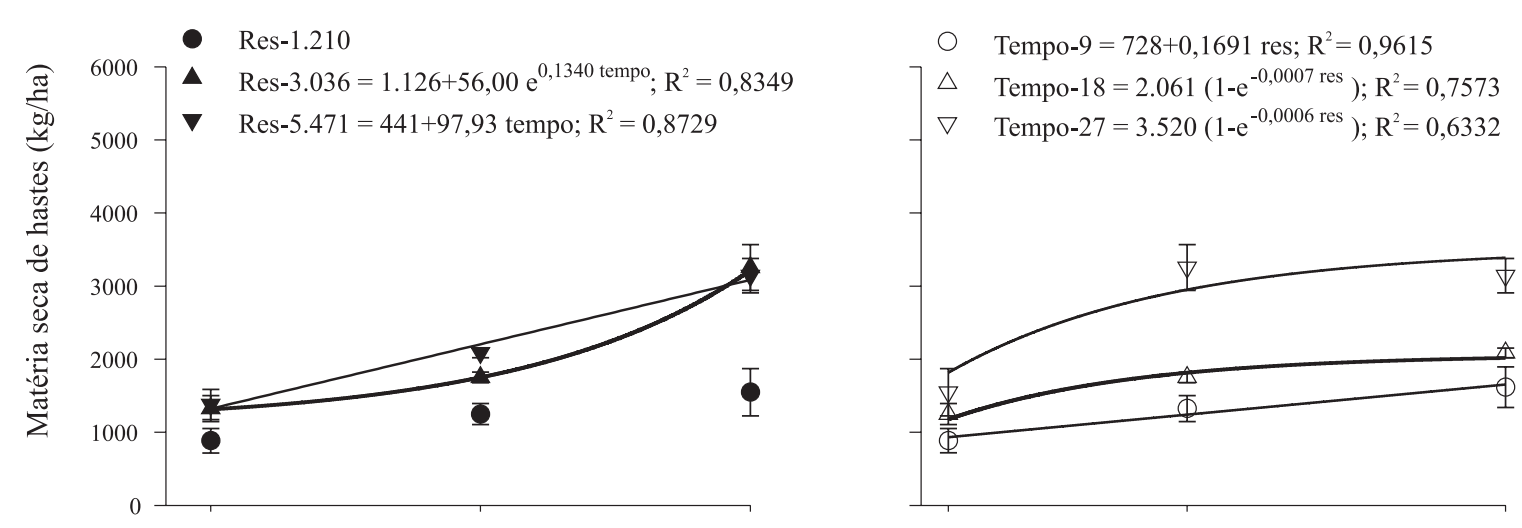

Verão
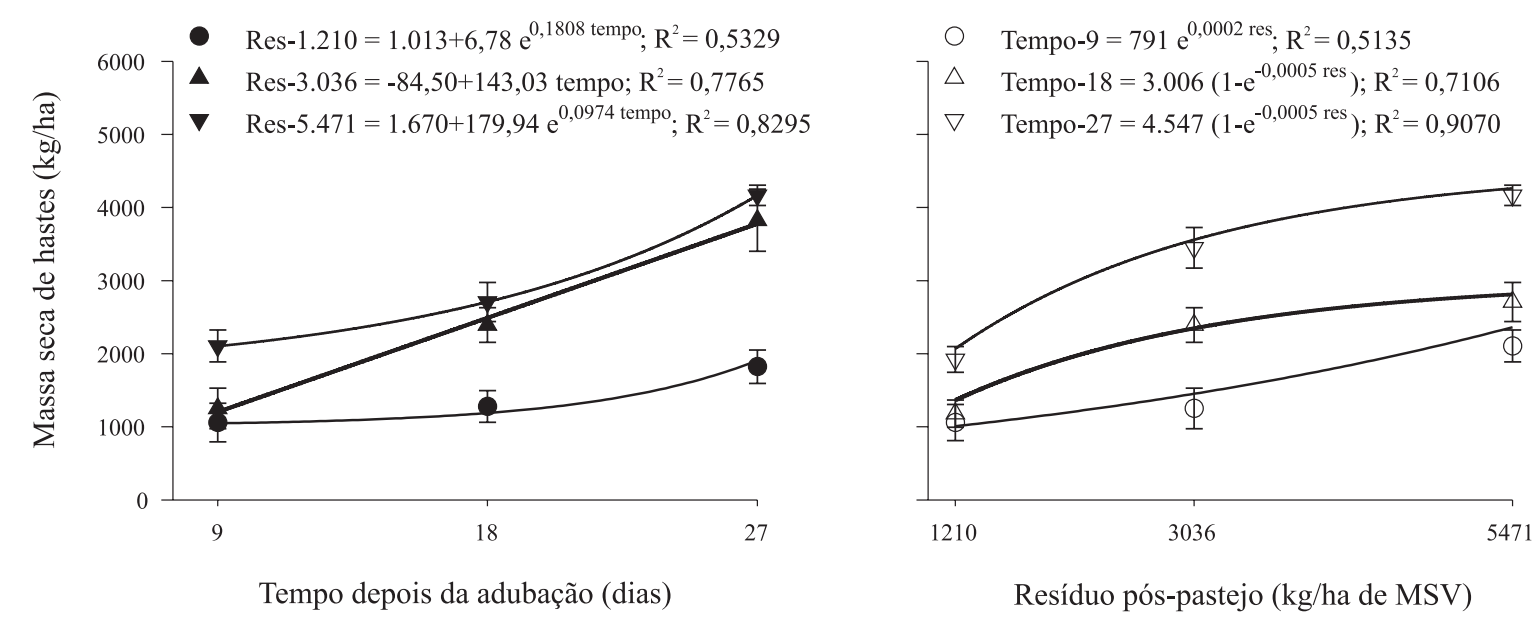

Figura 3. Efeito do resíduo pós-pastejo (res: 1.210, •; 3.036, $\mathbf{\Delta}$; e 5.471, $\mathbf{\nabla}$, em kg/ha de matéria seca de tecido verde) e do período pós-adubação (tempo: 9, o; 18, $\triangle$; e 27 dias $\nabla$ ), na matéria seca de hastes em pastagem de capimtanzânia na primavera e no verão. As equações apresentadas são significativas $(\mathrm{P}<0,05)$. As barras em cada ponto representam a média \pm desvio-padrão. 
acúmulo de hastes do que de folhas, particularmente durante o verão (Figuras 2 e 3). Esse comportamento possivelmente refletiu a presença de perfilhos de idade fisiológica mais avançada e, portanto, mais pesados, em pastagens manejadas sob regime de desfolha leniente (Santos, 2002). O aumento na MFH, no verão, também pode estar associado ao início da indução ao florescimento, pois perfilhos reprodutivos são mais pesados do que perfilhos vegetativos (Korte et al., 1984)

A relação $\mathrm{F} / \mathrm{H}$, no verão, diminuiu com o aumento do resíduo pós-pastejo $(\mathrm{F} / \mathrm{H}=1,0333-0,000055 \times$ resíduo; $\left.\mathrm{R}^{2}=0,8619 ; \mathrm{P}<0,0127\right)$. No entanto, na primavera, houve efeito da interação entre o resíduo pós-pastejo e o período pós-adubação sobre a relação $\mathrm{F} / \mathrm{H}$. Na primavera, a relação $\mathrm{F} / \mathrm{H}$ aumentou linearmente com o tempo depois da adubação quando o pastejo foi intenso (Figura 4a), porém, diminuiu de maneira exponencial com o incremento no resíduo pós-pastejo quando o período de 27 dias depois da adubação foi considerado (Figura 4b). Aos 18 dias depois da adubação, a resposta da relação $\mathrm{F} / \mathrm{H}$ foi quadrática, apresentando ponto de máximo em um resíduo pós-pastejo de $2.826 \mathrm{~kg} / \mathrm{ha}$ de MSV (Figura 4b).

O fato de a maior proporção de MFVP ser representada por hastes parece justificar a proposta de que o manejo de $P$. maximum deve centrar-se no controle de hastes, visando favorecer a qualidade da forragem facilitar o manejo da pastagem (Santos et al., 1999; San- tos, 2002). Entretanto, a redução na participação de hastes na pastagem não pode ser o único critério de manejo, pois, nessa condição pode-se penalizar, de maneira sensível, a produção de forragem, principalmente a de folhas. As correlações positivas e significativas $(\mathrm{P}<0,0001)$ entre MFF e MFH observadas, na primavera $(r=0,9131)$ e no verão $(r=0,9024)$, dão suporte a essa idéia. De acordo com Robson (1981), a presença de hastes influencia positivamente a produção de forragem, em razão de favorecer a distribuição de luz em camadas inferiores do dossel.

O comportamento errático da $\mathrm{MFH}$, principalmente em relação ao período de rebrota, mas, também, em função do resíduo pós-pastejo (Figura 3), ratifica a argumentação de que o manejo centrado exclusivamente no controle de hastes pode proporcionar resultados inconsistentes e, por vezes, desfavoráveis sobre a produção de forragem. Assim, critérios adicionais de manejo, como a MFF e a relação $\mathrm{F} / \mathrm{H}$ da pastagem, devem ser utilizados.

Em trabalho com três resíduos pós-pastejo $(816,2.548$ e $3.113 \mathrm{~kg} / \mathrm{ha}$ de MSV) em capim-tanzânia irrigado, no período de inverno, a utilização dos indicadores de manejo - minimização da participação de hastes e maximização da produção de folhas e da relação $\mathrm{F} / \mathrm{H}$ apresentou resultados satisfatórios (Martha Júnior, 2003). Neste estudo, a proposta de trabalhar com resíduos póspastejo entre 1.900 a $2.100 \mathrm{~kg} / \mathrm{ha}$ de MSV reduziria a

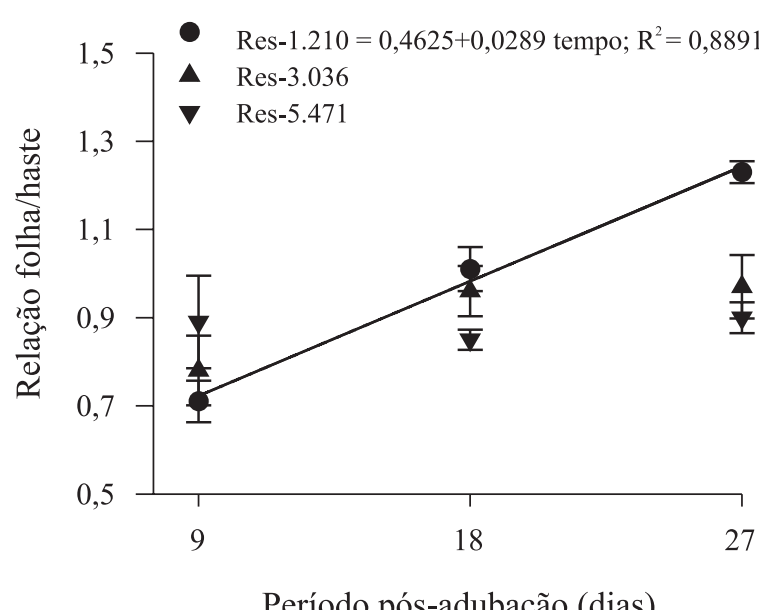

O $9 \mathrm{~d}$

$\triangle 18 \mathrm{~d}=0,8367+0,00013$ res- $2,3.10^{-8}$ res $^{2} ; R^{2}=0,8456$ $\nabla \quad 27 \mathrm{~d}=0,8966+3,3827 \mathrm{e}^{-0,0019}$ res $; \mathrm{R}^{2}=0,9115$

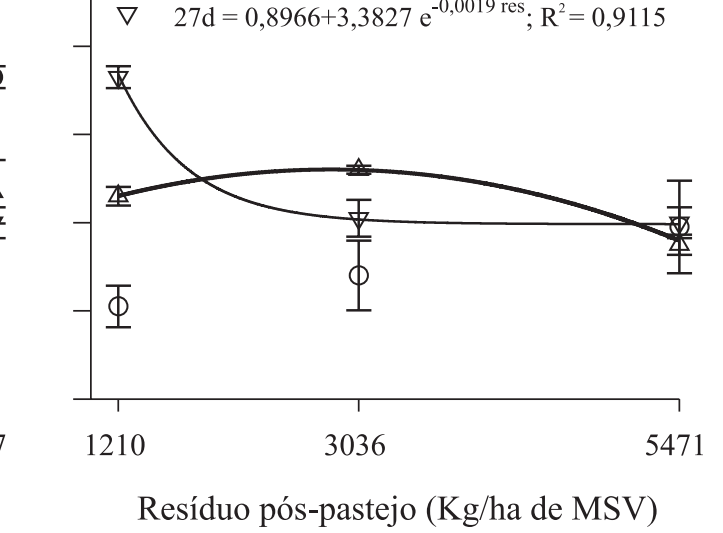

Figura 4. Efeito do resíduo pós-pastejo (res: 1.210, •; 3.036, ^; e 5.471, $\mathbf{\nabla}$, em kg/ha de tecido de matéria seca verde) e do período pós-adubação (tempo: 9,$0 ; 18, \Delta ;$ e 27 dias, $\nabla$ ), na primavera, sobre a relação folha/haste de pastagem de capim-tanzânia. As equações apresentadas são significativas $(\mathrm{P}<0,001)$. As barras em cada ponto representam a média \pm desvio-padrão. 
MFVP pela metade em relação ao maior resíduo póspastejo testado (3.113 kg/ha de MSV), mas não alteraria a produção de folhas.

A aplicação desta proposta de manejo não é facilmente equacionada na primavera e no verão. Considerando os 27 dias depois da adubação, observa-se que primar pela maximização da relação $\mathrm{F} / \mathrm{H}$ ou pela minimização da MFH indicaria que o manejo da pastagem, na primavera e no verão, deveria ter como meta resíduos pós-pastejo próximos a $1.210 \mathrm{~kg} / \mathrm{ha}$ de MSV (Figuras 3 e 4). Contudo, a manutenção desta massa de forragem residual tornaria a produtividade da pastagem insustentável no tempo (Penati, 2002), em razão da combinação de baixo IAF residual, status desfavorável de reservas fisiológicas na planta, pequeno crescimento de raízes subseqüentemente à desfolha e elevada eliminação de meristemas apicais (Gomide et al., 1979; Thronton \& Millard, 1996; Pagotto, 2001; Mello, 2002).

Em contrapartida, a maximização da produção de folhas estaria associada com resíduos pós-pastejo da ordem de $5.471 \mathrm{~kg} /$ ha de MSV, o que implicaria, também, na maximização da produção de hastes, levando a uma inevitável redução na relação $\mathrm{F} / \mathrm{H}$ da pastagem (Figuras 2, 3, 4). Ademais, com resíduos pós-pastejo lenientes, observam-se maiores perdas de forragem e menor capacidade de suporte da pastagem, que determinam produtividade animal menos satisfatória do que em intensidades de desfolha moderadas (Penati, 2002).

Em termos práticos, como nenhuma dessas propostas - pastejos intensos ou lenientes - são válidas, poder-se-ia propor como meta um resíduo pós-pastejo intermediário, em que houvesse equilíbrio entre a MFF e a MFH, possibilitando conciliar boa produtividade com valor nutritivo satisfatório da forrageira. Gomide (1994) apontou que essa condição seria obtida com a manutenção de uma relação $\mathrm{F} / \mathrm{H}$ ao redor de 1 , embora, do estudo de Penati (2002), depreenda-se que relações F/H de 0,8 a 1,0 teriam impactos semelhantes no desempenho dos animais em pastejo, desde que a disponibilidade de forragem fosse mantida em patamares elevados.

Considerando como ponto inicial para o manejo o intervalo de resíduos pós-pastejo correspondentes a relações $\mathrm{F} / \mathrm{H}$ entre 0,8 e 1,0, ter-se-ia, como meta, resíduos pós-pastejo de 1.650 a $3.100 \mathrm{~kg} / \mathrm{ha}$ de MSV e 1.500 $2.700 \mathrm{~kg} / \mathrm{ha}$ de MSV na primavera (Figura 5a) e no verão (Figura 5b), respectivamente. Na primavera, houve pouca variação na relação $\mathrm{F} / \mathrm{H}$ a partir do resíduo de $3.100 \mathrm{~kg} / \mathrm{ha}$ de MSV.

Essa proposta de manejo não deveria afetar de maneira expressiva a produção de forragem, principalmente a de folhas. Pelas equações apresentadas na Figura 2, considerando 27 dias depois da adubação nitrogenada, estima-se que na primavera, a redução do resíduo póspastejo para $30 \%$ a $57 \%$ (1.650 a $3.100 \mathrm{~kg} / \mathrm{ha}$ de MSV) do máximo valor testado (5.471 kg/ha de MSV) estaria associada com uma MFF equivalente a $72 \%$ a $83 \%$ da máxima produção. No verão, a diminuição da massa de forragem residual para $27 \%$ a $49 \%(1.500$ a $2.700 \mathrm{~kg} /$ ha de MSV) do máximo valor testado $(5.471 \mathrm{~kg} / \mathrm{ha}$ de MSV) implicaria em uma MFF equivalente a 71 a $80 \%$ da máxima produção. Nessas condições, a massa seca de hastes representaria $65 \%$ a $88 \%$ e $56 \%$ a $79 \%$ das máximas produções obtidas na primavera e no verão, respectivamente.
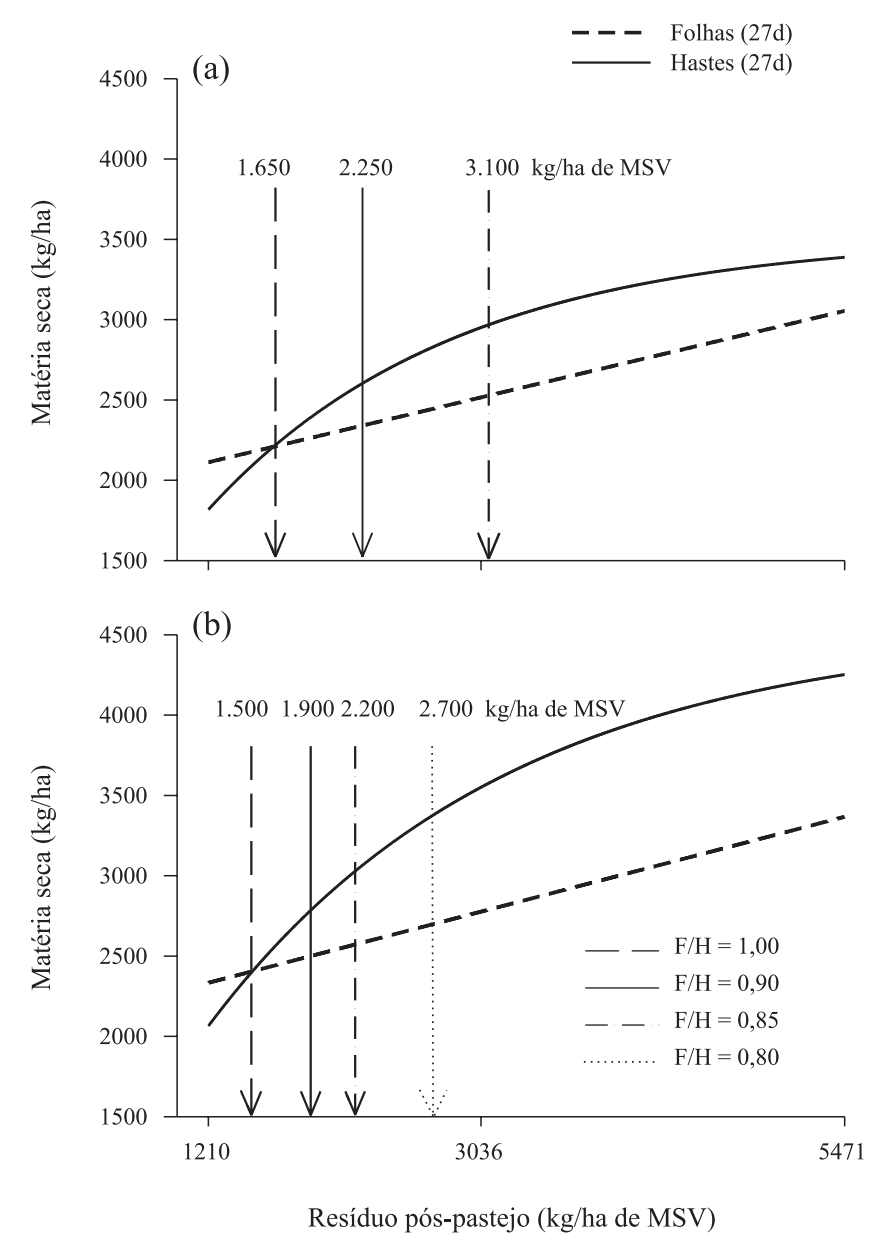

Figura 5. Matéria seca de hastes e de folhas e relação folha/ haste, aos 27 dias depois da adubação, na primavera (a) e no verão (b), em função de variações no resíduo pós-pastejo $(\mathrm{kg} / \mathrm{h}$ a de matéria seca de tecido verde - MSV). As equações apresentadas constam das Figuras 2 e 3. 
Tomando o valor médio das amplitudes de resíduo pós-pastejo propostas na Figura 5, calcula-se que a redução de 4,1 a 4,5 unidades no resíduo pós-pastejo determinaria a diminuição de uma unidade na MFF. Desse modo, a sugestão de se trabalhar com resíduos póspastejo de 1.650 a $3.100 \mathrm{~kg} / \mathrm{ha}$ de MSV, na primavera, e de 1.500 a $2.700 \mathrm{~kg} /$ ha de MSV, no verão, parece viável, embora o controle da massa seca de hastes não tenha sido efetivo, contrariando o comportamento observado no período de inverno (Martha Júnior, 2003).

Contudo, uma vez que o resíduo pós-pastejo tende a aumentar ao longo da estação de pastejo (Penati, 2002 Quadros et al., 2002), o máximo resíduo pós-pastejo na primavera deve ser menor ou, no mínimo, igual ao limite superior proposto para o verão, de $2.700 \mathrm{~kg} / \mathrm{ha}$ de MSV (Figura 5). Por esse mesmo motivo, o limite inferior de massa de forragem residual proposto para o verão deve ser igual ou superior ao indicado para a primavera, de $1.650 \mathrm{~kg} / \mathrm{ha}$ de MSV.

Portanto, o resíduo pós-pastejo na primavera e no verão deveria situar-se entre 1.650 e $2.700 \mathrm{~kg} / \mathrm{ha}$ de MSV. Com esses níveis de massa de forragem residual, ter-se-ia, potencialmente, a manutenção da estrutura da pastagem e da qualidade da forragem em patamares favoráveis ao desempenho do animal. Assim, não haveria alteração substancial da produção de folhas, por não haver comprometimento expressivo dos processos fisiológicos da planta forrageira imediatamente depois do pastejo (Pagotto, 2001; Mello, 2002). Pode-se inferir também, que nessa amplitude de massa de forragem residual não ocorreria redução significativa na capacidade de suporte da pastagem, em razão do aumento da eficiência de colheita de forragem e da diminuição das perdas decorrentes do pastejo, conforme constatado por Penati (2002).

\section{Conclusões}

1. A intensidade de desfolha (pastejo intenso, moderado ou leniente) altera os componentes da produção forrageira; desfolhas lenientes, em particular, promovem uma elevada proporção de hastes na massa seca de forragem da pastagem.

2. O resíduo pós-pastejo em pastagem irrigada de capim-tanzânia, considerando um ciclo de pastejo de 36 dias e níveis elevados de fertilização nitrogenada, deve ser de 1.650 a $2.700 \mathrm{~kg} / \mathrm{ha}$ de matéria seca de tecido verde de forragem para assegurar que a produção de folhas e a relação folha/haste se aproximem do máximo.

\section{Referências}

BARBOSA, R.A.; NACIMENTO JUNIOR, D.; EUCLIDES, V.P.B.; REGAZZI, A.J.; FONSECA, D.M. Características morfogênicas e acúmulo de forragem do capim-Tanzânia (Panicum maximum Jacq. cv. Tanzânia) em dois resíduos forrageiros pós-pastejo. Revista Brasileira de Zootecnia, v.31, p.583-593, 2002.

CECATO, U.; CANO, C.C.P.; CANTO, M.W.; RODRIGUES, A.B.; JOBIM, C.C.; SANTOS, G.T.; PEPILIASCO, L.S.; NASCIMENTO, W.G. Disponibilidade de massa seca e conteúdo de minerais em capim-Tanzânia (Panicum maximum Jacq.) pastejado em diferentes alturas. In: REUNIÃO ANUAL DA SOCIEDADE BRASILEIRA DE ZOOTECNIA, 39., 2002, Recife. Anais. Recife: SBZ, 2002. CD-ROM.

CECATO, U.; CASTRO, C.R.C.; CANTO, M.W.; PETERNELLI, M.; ALMEIDA JÚNIOR, J.; JOBIM, C.C.; CANO, C.C.P. Perdas de forragem em capim-Tanzânia (Panicum maximum Jacq. cv. Tanzânia-1) manejado sob diferentes alturas sob pastejo. Revista Brasileira de Zootecnia, v.30, p.295-301, 2001.

CECATO, U.; MACHADO, A.O.; MARTINS, E.N.; PEREIRA, L.A.F.; BARBOSA, M.A.A.F.; SANTOS, G.T. Avaliação da produção e de algumas características da rebrota de cultivares e acessos de Panicum maximum Jacq. sob duas alturas de corte. Revista Brasileira de Zootecnia, v.29, p.660-668, 2000.

CORSI, M.; MARTHA JÚNIOR, G.B.; PAGOTTO, D.S. Sistema radicular: dinâmica e resposta a regimes de desfolha. In: REUNIÃO ANUAL DA SOCIEDADE BRASILEIRA DE ZOOTECNIA. A produção animal na visão dos brasileiros. Piracicaba: Fealq, 2001. p. $838-852$

EUCLIDES, V.P.B.; MACEDO, M.C.M.; VIEIRA, A.; OLIVEIRA, M.P. Evaluation of Panicum maximum cultivars under grazing. In: INTERNATIONAL GRASSLAND CONGRESS, 17., 1993, Palmerston North. Proceedings. Palmerston North: New Zealand Grassland Association, 1993. p.1999-2000.

GOMIDE, J.A. Formação e utilização de capineira de capim-elefante. In: CARVALHO, M.M.; ALVIM, M.J.; XAVIER, D.F; CARVALHO, L.A. (Ed.). Capim-elefante: produção e utilização. Brasília: Embrapa-SPI, 1994. p.79-112.

GOMIDE, J.A.; OBEID, J.A.; RODRIGUES, L.R.A. Fatores morfofisiológicos de rebrota do capim colonião (Panicum maximum Jacq.). Revista da Sociedade Brasileira de Zootecnia, v.8, p.532562, 1979.

KORTE, C.J.; WATKIN, B.R.; HARRIS, W. Effects of the timing and intensity of spring grazings on reproductive development, tillering, and herbage production of perennial ryegrass dominant pasture. New Zealand Journal of Agricultural Research, v.27, p.135-149, 1984

MARTHA JÚNIOR, G.B. Produção de forragem e transformações do nitrogênio do fertilizante em pastagem irrigada de capim Tanzânia. 2003. 149p. Tese (Doutorado) - Escola Superior de Agricultura Luiz de Queiroz, Piracicaba.

MELLO, A.C.L. Respostas morfofisiológicas do capim Tanzânia (Panicum maximum Jacq. cv. Tanzânia) irrigado à intensidade de desfolha sob lotação rotacionada. 2002. 57p. Tese (Doutorado) - Escola Superior de Agricultura Luiz de Queiroz, Piracicaba. 
PAGOTTO, D.S. Comportamento do sistema radicular do capim Tanzânia (Panicum maximum Jacq.) sob irrigação e submetido a diferentes intensidades de pastejo. 2001. 51p. Dissertação (Mestrado) - Escola Superior de Agricultura Luiz de Queiroz, Piracicaba.

PARSONS, A.J.; CHAPMAN, D.F. The principles of pasture growth and utilization. In: HOPKINS, A. (Ed.). Grass: its production and utilization. Oxford: Blackwell Science, 2000. p.31-89.

PENATI, M.A. Estudo do desempenho animal e produção do capim Tanzânia (Panicum maximum Jacq.) em um sistema rot cionado de pastejo sob irrigação em três níveis de resíduo póspastejo. 2002. 117p. Tese (Doutorado) - Escola Superior de Agricultura Luiz de Queiroz, Piracicaba.

QUADROS, D.G.; RODRIGUES, L.R.A.; FAVORETTO, V.; MALHEIROS, E.B ; HERLING, V.R ; RAMOS, A.K.B. Componentes da produção de forragem em pastagens dos capins Tanzânia e Mombaça adubadas com quatro doses de NPK. Revista Brasileira de Zootecnia, v.31, p.1333-1342, 2002.

ROBSON, M.J. Potential production: what is it and can we increase it? In: WRIGHT, C.E. (Ed). Plant physiology and herbage production. Nottingham: British Grassland Society, 1981. p.5-18.
SANTOS, P.M. Controle do desenvolvimento das hastes no capim Tanzânia: um desafio. 2002. 98p. Tese (Doutorado) - Escola Superior de Agricultura Luiz de Queiroz, Piracicaba.

SANTOS, P.M.; CORSI, M.; BALSALOBRE, M.A.A. Efeito da frequiência de pastejo e da época do ano sobre a produção e qualidade em Panicum maximum cvs. Tanzânia e Mombaça. Revista Brasileira de Zootecnia, v.28, p.244-249, 1999.

SAS INSTITUTE (Cary, Estados Unidos). SAS/STAT user's guide, version 6. $4^{\text {th }}$ ed. Cary, 1989. 943p.

THORNTON, B.; MILLARD, P. Effects of severity of defoliation on root functioning in grasses. Journal of Range Management, v.49, p.443-447, 1996

TOSI, P. Estabelecimento de parâmetros agronômicos para o manejo e eficiência de utilização de Panicum maximum cv. Tanzânia 1 sob pastejo rotacionado. 1999. 103p. Dissertação (Mestrado) - Escola Superior de Agricultura Luiz de Queiroz, Piracicaba.

ZIMMER, A.H. Efeito de níveis de nitrogênio e de resíduos pós-pastejo sobre a produção, a estrutura e a qualidade das cultivares Aruana e Vencedor de Panicum maximum Jacq. 1999. 208p. Tese (Doutorado) - Universidade Estadual Paulista, Jaboticabal.

Recebido em 11 de junho de 2003 e aprovado em 6 de maio de 2004 